\title{
A REGULAÇÃO ESTATAL DOS INVESTIMENTOS EM PESQUISA NO ENSINO SUPERIOR BRASILEIRO
}

\author{
Daniel Guerrini
}

\section{RESUMO}

Microdados do censo da educação superior de 2010, do Instituto Nacional de Estudos e Pesquisas Educacionais (INEP), são usados para investigar como o Estado brasileiro e os grupos acadêmicos regulam os investimentos em pesquisa no país. Cruzaram-se dados de investimentos em pesquisa das instituições de ensino superior (IES) com as categorias em que tais instituições são divididas, além de se analisarem os critérios utilizados pela Coordenação de Aperfeiçoamento de Pessoal do Ensino Superior (CAPES) para dar acesso às IES ao seu banco de dados. As categorias importam na medida em que indicam se as instituições são públicas ou privadas, e também qual o grau de autonomia que o Estado confere às mesmas, em função de serem faculdades, centros universitários, ou universidades. 0 sentido dessas divisões será mostrado com a análise das leis que regulam o ensino superior (ES) no Brasil. Conclui-se que as restrições à autonomia institucional impostas pelo Estado a mais de $80 \%$ das IES no país não impedem que as mesmas invistam em pesquisa. Esses investimentos, entretanto, são realizados sem parâmetros institucionais claros e são incentivados pelas agências acadêmicas de coordenação do ES no Brasil, que endossam um modelo de universidade de pesquisa para todo o sistema.

Palavras-chave: Ensino superior. Pesquisa científica. Instituições de ensino superior.

\footnotetext{
${ }^{1}$ Professor do Departamento de Ciências Sociais da Universidade Estadual de Londrina e Doutorando pelo Programa de Pós-Graduação em Sociologia da Universidade Federal do Rio Grande do Sul, Brasil. daniel_guerrini@hotmail.com
} 


\title{
STATE REGULATION FOR INVESTMENTS IN THE BRAZILIAN GRADUATE EDUCATION RESEARCH
}

\begin{abstract}
Micro data from 2010 graduate education census of the National Institute of Educational Studies and Research (Instituto Nacional de Estudos e Pesquisas Educacionais - INEP) are used to investigate how the Brazilian state and academic groups regulate research investment in the country. Data from graduate education institutions' research investments and their categories were crosschecked. We also analyzed the criteria used by the Brazilian Federal Agency for Support and Evaluation of Graduate Education (Coordenação de Aperfeiçoamento de Pessoal do Ensino Superior - CAPES) to allow graduate education institutions access to CAPES database. The categories are relevant as they indicate whether the institutions are public or private. They also indicate to what extent the institutions have been given autonomy by the state, by virtue of their being faculties, university centers or universities. The meaning of these divisions will be presented in the analysis of law which regulate graduate education in Brazil. We conclude that the restrictions on institutional autonomy imposed by the State to more than $80 \%$ of graduate education institutions in the country do not prevent them from investing in research. However, these investments lack clear institutional parameters, and they are encouraged by the academic agencies that coordinate graduate education in Brazil, which endorse a research university model for the entire system.
\end{abstract}

Keywords: Graduate education. Scientific research. Graduate education institutions.

\section{INTRODUÇÃO}

$\mathrm{N}$

este artigo analisou-se o Sistema de Ensino Superior (SES) brasileiro a partir dos microdados do censo do ensino superior de 2010, conduzido pelo Instituto Nacional de Estudos e Pesquisas Educacionais (INEP) ${ }^{2}$. Mais especificamente, foram analisados os dados relativos aos investimentos em pesquisa e desenvolvimento das instituições de ensino superior (IES) no Brasil, observando os dados da Coordenação de Aperfeiçoamento de Pessoal do Ensino Superior (CAPES) e as normas que amparam e regulam estas IES e seus investimentos. Estas análises foram realizadas com o auxílio do software IBM SPSS Statistics 19 de computação estatística.

Com os microdados do Censo do Ensino Superior de 2010 foi possível analisar as condições que as IES dispõem para realizar pesquisa, uma vez que um montante significativo de recursos é investido com este objetivo (no ano de 2010 foram investidos

${ }^{2}$ Disponíveis em: <http://portal.inep.gov.br/basica-levantamentos-acessar>. 
$\mathrm{R} \$ 703.644 .957,25$ em pesquisa e desenvolvimento ${ }^{3}$ ). A seleção das variáveis para a análise teve o objetivo de observar os critérios utilizados pelos quadros administrativos e políticos do Estado e também pelos grupos acadêmicos para coordenar esses investimentos e para garantir a qualidade das pesquisas financiadas. Para analisar a coordenação de agentes do Estado se selecionaram as variáveis que diferenciam as IES em categorias administrativas e acadêmicas, definidas nas normas federais sobre 0 ensino superior. Essas normas foram analisadas aqui também para que se pudesse extrair o sentido dado às categorias presentes nas variáveis do censo. Já para investigar a coordenação de agentes acadêmicos selecionou-se a variável de acesso ao Portal CAPES (da Coordenação de Aperfeiçoamento de Pessoal do Ensino Superior - CAPES). Analisaram-se os critérios definidos pela CAPES para dar acesso às IES ao seu portal de banco de dados e periódicos científicos para, também, extrair o sentido da coordenação que essa agência impõe sobre o sistema de ensino superior brasileiro ${ }^{4}$.

\footnotetext{
${ }^{3} 0$ universo de IES analisado neste artigo não representa o total dos casos (2.378) presentes nos microdados do Censo do Ensino Superior de 2010. Optei por excluir duas IES (cujos códigos são 530 e 5013 nos microdados do censo), uma faculdade e outra um centro universitário, públicas estaduais, que registram um investimento de 300 e 100 milhões de reais em pesquisa, respectivamente. Estes valores estão muito acima da média das IES, quanto mais para os casos de faculdades e centros universitários, gerando distorções na análise dos dados para este artigo. Também excluí todos os centros e institutos de educação tecnológica. A educação tecnológica constitui um ramo diferente do ensino superior tradicional acadêmico. Muitos países dispõem dessa mesma separação em seus SES, em que um ramo se especializa na formação acadêmica, enquanto o outro na formação técnica e mais estritamente profissional, orientada já para postos específicos de trabalho. No Brasil esse ramo da educação encontra-se em desenvolvimento e seu papel é pouco claro, pois mesmo o ramo acadêmico é resultado de uma tradição de escolas superiores voltadas para formação profissional. Ademais, dados do censo da educação superior mostram que mesmo os institutos tecnológicos oferecem cursos de bacharelado e licenciatura, tornando sua distinção em relação ao ramo acadêmico do ES menos clara ainda. Por fim, a lei da educação 9.394 de 1996 e o Decreto Presidencial 5773 de 2006 regulam apenas faculdades, centros universitários e universidades, tendo a educação técnica legislação específica. Utilizo neste artigo as duas normas mencionadas. Dessa forma, o universo analisado neste artigo é de 2.339 IES, divididas entre faculdades, centros universitários e universidades tão somente. 0 montante de investimentos em pesquisa e desenvolvimento apresentado refere-se a este universo de IES.

${ }^{4}$ Com a conclusão deste trabalho viu-se a possibilidade de analisar os dados acerca do investimento em pesquisa relacionando-os não apenas às categorias administrativas e acadêmicas das IES, mas em relação ao seu porte e orçamento. Esses dados seriam relevantes na medida em que permitiriam observar uma diferenciação maior no universo analisado, mostrando, talvez, que IES que investem uma soma pequena, podem ter um percentual de investimentos em relação ao seu orçamento bastante elevado. Isso certamente alteraria a compreensão de "quanto" determinadas instituições investem em pesquisa, permitindo até observar ilhas de excelência acadêmica (BALBACHEVSKY; HOLZHACKER, 2005) em meio a IES não tradicionalmente reconhecidas como sendo voltadas à pesquisa. Entretanto, isso exigiria um novo trabalho e nessa fase buscou-se apenas extrair o sentido das diferentes formas de coordenação do sistema de ensino superior brasileiro, colocados em prática tanto pelos quadros políticos e administrativos do
} 
Através das análises se observaram investimentos em pesquisa e desenvolvimento realizados à revelia de parâmetros legais e institucionais. Alguns dos resultados da exploração inicial dos dados foram mesmo contraintuitivos. Primeiramente por iniciar a análise com a visão comum de que os centros de excelência em pesquisa no Brasil estão nas universidades públicas, criando a expectativa de observar nesse grupo uma grande concentração de investimentos. Porém, mais de $50 \%$ dos investimentos em pesquisa são realizados por IES privadas. Segundo, por saber que a lei sobre o ensino superior não garante autonomia institucional para realização de pesquisa a faculdades e centros universitários. A lei não exige das faculdades um quadro docente com um mínimo de titulação e, mesmo assim, faculdades públicas e privadas investem em torno de 220 milhões em pesquisa e desenvolvimento.

Este artigo investigou esses fenômenos mais a fundo. Na primeira sessão são apresentadas as normas que regulam o ensino superior brasileiro, sua terminologia e 0 significado das mesmas para o SES brasileiro, uma vez que o censo utiliza categorias presentes nas leis para construir suas variáveis. Na segunda sessão é apresentada a análise dos dados formulando, no inicio do mesmo, algumas questões que nortearam a investigação. Nesta mesma seção são apresentados microdados do censo, relacionando basicamente 0 volume de investimentos em pesquisa com as diferentes categorias de IES, chegando assim a um panorama geral da realidade desses investimentos. São apresentadas tabelas somente com as IES que investem em pesquisa, que representam em torno de 40\% do total de instituições, introduzindo a variável de acesso ao portal CAPES. Para tanto se explicitam e analisam os critérios que essa agência acadêmica de coordenação da educação superior utiliza para permitir o acesso ao portal. Por fim, conclui-se o artigo observando a existência de critérios detalhados que ambicionam regular o SES brasileiro de maneira bastante estrita. Porém, isso não impede o sistema como um todo de investir uma quantidade volumosa de recursos em pesquisas sem parâmetros institucionais claros. Parece haver um conflito entre as formas de coordenação analisadas, com sobreposição de critérios e conflitos de direcionamento entre a coordenação estatal e a acadêmica.

\section{A LeI da EdUCAÇÃo E A TERMinOlOGia do Sistema de ENSINo SUPERIOR BRASILEIRO}

Comparado a outros países, o sistema brasileiro apresenta algumas particularidades relativas à denominação administrativa e acadêmica das IES 5 .

Estado, na forma de normas federais, quanto pelos grupos profissionais acadêmicos através dos critérios que a CAPES utiliza para dar acesso ao seu portal de periódicos e banco de dados.

${ }^{5}$ Para uma breve referência à divisão entre ES técnico/tecnológico e acadêmico, ver nota 2. Esta divisão, corrente nos SES de vários países, não fará parte das discussões deste artigo. 
Administrativamente, as IES são divididas em privadas (com e sem fins lucrativos) e públicas estaduais, federais e municipais. A divisão entre IES públicas e privadas não apresenta maiores dificuldades à sua compreensão, referindo-se à personalidade jurídica da instituição e sua consequente dependência administrativa do Estado ou de entes de direito privado. Uma perspectiva histórica dessa divisão, muito bem analisada por Durham (2003), é importante para a compreensão da história e da dinâmica de desenvolvimento do SES brasileiro.

As IES privadas e as federais compõem o Sistema Federal de Ensino Superior, sendo todas avaliadas e supervisionadas pela União. A legislação que rege as mesmas é a lei 9.394 de 1996 e o Decreto Presidencial 5.773 de 2006 (BRASIL, 2006). A lei 9.394 é relativa a toda a educação, contendo seções para cada nível de ensino, inclusive 0 superior. Entretanto, segundo a mesma lei, as unidades da Federação podem ser mantenedoras de IES estaduais, devendo para tanto formular suas próprias normas, que devem estar em harmonia com as normas federais. Neste caso, a União delega para os Estados e/ou para o Distrito Federal a atribuição de coordenar suas próprias instituições. No caso das IES municipais esta delegação não está prevista. A lei abre a possibilidade de integração entre municípios e Estados, cabendo aos primeiros apenas a formulação de normas complementares.

Mas os dados dos censos de 1991 a 2009, reunidos pelo INEP (2010) em uma única tabela, mostrando a evolução de aspectos do SES, parecem sugerir uma lógica para as IES municipais semelhante à da criação de instituições locais no período entre 1945 e 1964, quando, segundo Durham (2003), elites locais criavam instituições municipais com o objetivo de posteriormente demandar ao governo federal sua incorporação ao sistema federal. A partir de 1991, observa-se um aumento do número de cursos presenciais ofertados por IES municipais, com uma interrupção e queda bruscas entre 1999 e 2000. 0 número de matriculados também cai entre 1999 e 2000 e novamente em 2009, ainda que os cursos ofertados não registrem queda em 2009. Em termos relativos, o número de cursos ofertados por IES municipais representava $6,35 \%$ do total em 1991 e em 2009 esse percentual caiu para 2,67\%. Além de um aumento inconstante do número de cursos, sua representatividade no sistema como um todo caiu significativamente. Uma provável hipótese explicativa para a queda do número de instituições nos anos 1999 e 2000 é a incorporação, pelos sistemas federais e/ou estaduais, daquelas cujos municípios não tenham condições técnicas ou financeiras de mantê-las, após as terem criado por outras motivações políticas. Além disso, segundo a lei da educação a prioridade desta unidade da federação é financiar a educação básica.

A lei da educação também estabelece uma divisão interna ao SES baseada em categorias acadêmicas, que fazem distinção entre instituições de ensino superior, com base nas prerrogativas de autonomia institucional reconhecidas pelo Estado a cada categoria, independentemente de serem públicas ou privadas. Essa divisão também 
pretende diferenciar o SES, pois deixa claro que uma das categorias de IES deve priorizar o ensino ao invés da pesquisa acadêmica. As universidades são aquelas instituições que devem combinar pesquisa, ensino e extensão, tendo todas as prerrogativas de autonomia institucional garantidas na lei. Existem ainda os centros universitários e as faculdades. As últimas são IES não autônomas. Elas não podem abrir cursos, expandir os campos ou conferir diplomas sem prévia autorização dos quadros administrativos do Estado. Todas as mudanças pretendidas pelas faculdades em relação ao projeto inicial de sua criação (cursos ofertados, número de vagas, diplomas conferidos, estrutura física, etc.) devem ser submetidas à avaliação do Ministério da Educação (MEC) para serem aprovados previamente. Os centros universitários, por sua vez, têm reconhecidas algumas prerrogativas de autonomia, podendo abrir novos cursos e mudar o número de vagas ofertadas sem prévia autorização do MEC.

Enquanto isso, as universidades desfrutam, por lei, de plena autonomia institucional. De acordo com o artigo 53 da lei 9.394, as universidades podem:

I - criar, organizar e extinguir, em sua sede, cursos e programas de educação superior previstos nesta Lei, obedecendo às normas gerais da União e, quando for o caso, do respectivo sistema de ensino;

II - fixar os currículos dos seus cursos e programas, observadas as diretrizes gerais pertinentes;

III - estabelecer planos, programas e projetos de pesquisa científica, produção artística e atividades de extensão;

IV - fixar o número de vagas de acordo com a capacidade institucional e as exigências do seu meio;

$\mathrm{V}$ - elaborar e reformar os seus estatutos e regimentos em consonância com as normas gerais atinentes;

VI - conferir graus, diplomas e outros títulos;

VII - firmar contratos, acordos e convênios;

VIII - aprovar e executar planos, programas e projetos de investimentos referentes a obras, serviços e aquisições em geral, bem como administrar rendimentos conforme dispositivos institucionais;

IX - administrar os rendimentos e deles dispor na forma prevista no ato de constituição, nas leis e nos respectivos estatutos;

$X$ - receber subvenções, doações, heranças, legados e cooperação financeira resultante de convênios com entidades públicas e privadas. 
De acordo com o Decreto Presidencial 5.773 (BRASIL, 2006), que regula administrativamente as funções do sistema federal de ensino superior com base no que está disposto na lei 9.394 (BRASIL, 1996), os centros universitários estão autorizados a criar, organizar e extinguir cursos e programas de ensino superior sem prévia autorização do poder público. Assim, das prerrogativas de autonomia acima citadas eles detêm apenas a primeira. As restantes são exclusivas das universidades. Além disso, essas normas definem que os centros universitários devem buscar a excelência no ensino, demonstrando uma tentativa de diferenciar o SES entre IES voltadas à pesquisa e IES voltadas ao ensino e não uma mera hierarquia entre elas. Para isso, entretanto, controla com mais rigor os centros universitários, conferindo plena autonomia às universidades.

Mais que isso, a garantia da autonomia didático-científica, segundo a lei da educação, está referida apenas para o caso de universidades. No mesmo artigo 53 da lei 9.394 pode-se ler "para garantir a autonomia didático-científica das universidades", seguido de mais uma lista de liberdades desfrutadas pelas universidades para garantirlhes esta autonomia. No caso dos centros universitários e das faculdades, nada a este respeito é mencionado (BRASIL, 1996). Isto deixa em aberto a questão de se docentes e pesquisadores nestes dois tipos de IES desfrutam de liberdade acadêmica (de pesquisar e ensinar), ou se em alguma eventualidade a avaliação, regulação, credenciamento e registro destas IES e seus cursos pelas autoridades do MEC pode interferir na sua autonomia didático-acadêmica.

De acordo com o citado decreto 5.773, a distinção entre faculdades, centros universitários e universidades está ligada à organização e prerrogativas de autonomia de cada tipo de instituição. 0 sistema é estruturado a partir de uma escala de prerrogativas de autonomia garantidas às IES. Segundo a perspectiva que aparece no decreto, as IES devem iniciar como faculdades, passando por centros universitários, podendo subir gradativamente até atingirem 0 status de universidades. 0 processo todo, até 0 credenciamento como universidade, leva no mínimo 11 anos desde o primeiro credenciamento como faculdade, a depender das avaliações realizadas pelos órgãos competentes do Ministério e do deferimento dos pedidos de credenciamento das IES pelos mesmos órgãos. Para se tornarem centros universitários, as IES devem apresentar um terço do corpo docente com titulação de mestres e/ou doutores e um quinto com tempo integral. Como última etapa, as IES podem ser credenciadas como universidades se dispuserem de um terço do corpo docente com titulação de mestrado e/ou doutorado e um terço do corpo docente em regime de dedicação integral, além de requerimentos administrativos previstos no decreto.

A particularidade desse sistema é que universidades públicas são criadas por ato legislativo sem terem de passar por todo o processo de credenciamento e recredenciamento a que estão sujeitas as IES privadas, ou de unidades da Federação que não tenham condições de financiar desde 0 início uma universidade com as exigências 
descritas acima. Isto abre claramente uma vantagem das IES públicas em relação às IES privadas, especialmente aquelas criadas recentemente, na dinâmica de disputa por prestígio e recursos do sistema. Sabe-se que as atuais IES privadas que têm tradição na pesquisa acadêmica e detêm prestígio no SES foram criadas em meados do século XX, e por isso não foram objeto das regulações previstas nas normas em análise.

0 que será demonstrado com a análise dos dados, entretanto, é que as faculdades e centros universitários investem em pesquisa a despeito desta não ser uma prerrogativa de autonomia de que desfrutam. Isso não implica uma proibição legal, mas como organizar pesquisa científica não constitui uma prerrogativa de autonomia sua, não existem mecanismos normativos capazes de estabelecer parâmetros dentro dos quais esses recursos serão investidos ou essas pesquisas serão realizadas. As faculdades, por exemplo, não necessitam investir em recursos humanos nos padrões mínimos exigidos por lei das universidades e centros universitários. Os centros, por sua vez, têm como objetivo estabelecido em lei serem instituições de excelência no ensino. Porque, então, tanto se investe em pesquisa por essas categorias de IES?

\section{ANÁLISE DOS DADOS DO CENSO DE 2010}

A seguir define-se a questão que norteou a análise. Quais são os parâmetros definidos pelo Estado que balizam investimentos em pesquisa e desenvolvimento pelas IES brasileiras e quais os mecanismos de controle e supervisão que o mesmo dispõe para que tais parâmetros sejam seguidos?

Pelo exposto na seção anterior já se sabe que as universidades são alvo de algumas exigências para desfrutarem das prerrogativas de autonomia. Das faculdades não são exigidas a contratação de docentes com mestrado e/ou doutorado e com adicional de dedicação exclusiva, além de não desfrutarem das prerrogativas de autonomia próprias das universidades, ou mesmo dos centros universitários. Desses últimos é exigida a contratação de $1 / 3$ de seu corpo docente com mestrado e/ou doutorado e 1/5 dos mesmos com dedicação integral, sendo que essas instituições desfrutam da autonomia de criar cursos e vagas, devendo buscar a excelência no ensino, segundo a lei da educação.

Existe nas normas citadas uma expectativa de que as faculdades se desenvolvam até atingirem o status de universidades e que este processo seja controlado. No entanto isto aparece como um mecanismo de controle de qualidade do sistema, as IES públicas não necessitam passar por todo o processo de credenciamento e recredenciamento para se tornarem universidades, podendo ser criadas já com esse status por atos legislativos. E mesmo as faculdades, públicas ou privadas não esperam chegar ao patamar de universidades para investir, às vezes pesadamente, em pesquisa e desenvolvimento. Não 
existe exigência para que as IES subam os degraus da autonomia institucional levando a vantagem, mantendo-se na base da pirâmide, de não serem obrigadas a investir no seu corpo docente.

Assim, investigou-se nos dados do censo a relação entre investimentos em pesquisa e as diferentes categorias de IES, tanto acadêmicas como administrativas, com base nas seguintes questões: Quanto as faculdades e centros universitários investem em pesquisa? Nestas categorias, quantas delas pertencem ao setor privado? Existe diferença entre faculdades e centros universitários públicos e privados no que diz respeito a esses investimentos? Quantas dessas IES que investem em pesquisa têm acesso a bases de dados científicos?

$\mathrm{Na}$ tabela 01 apresenta-se um panorama geral das Instituições de Ensino Superior (IES) por categorias administrativas, a frequência de cada categoria e sua representatividade em relação ao total.

Tabela 1 - IES por categorias administrativas

\begin{tabular}{lcccc}
\hline & Frequência & Porcentagem & $\begin{array}{c}\text { Porcentagem } \\
\text { Válida }\end{array}$ & $\begin{array}{c}\text { Porcentagem } \\
\text { Acumulada }\end{array}$ \\
\hline Privada com fins lucrativos & 951 & 40.7 & 40.7 & 40.7 \\
Privada sem fins lucrativos & 1149 & 49.1 & 49.1 & 89.8 \\
Pública Estadual & 106 & 4.5 & 4.5 & 94.3 \\
Pública Federal & 62 & 2.7 & 2.7 & 97.0 \\
Pública Municipal & 71 & 3.0 & 3.0 & 100.0 \\
Total & 2339 & 100.0 & 100.0 & \\
\hline
\end{tabular}

Fonte: Instituto Nacional de Estudos e Pesquisas Educacionais (2010).

0 sistema é composto de 2.339 IES, das quais 89,8\% são privadas. A concentração do ensino superior brasileiro no setor privado é conhecida e debatida em diversos trabalhos (CALDERON; LOURENÇO, 2011; CUNHA, 2004; DURHAM, 2003; GRAMANI, 2008; SCHWARTZMAN, 2004). Esta divisão é temática corrente na literatura sobre o ES brasileiro. A dificuldade do Estado em coordenar adequadamente ou estabelecer parâmetros de qualidade para as IES privadas, as tem levado a assumir um papel de

\footnotetext{
${ }^{6}$ Pelos dados do censo é possível saber quais IES tem acesso ao Portal CAPES, o maior portal de acesso a diversas bases de dados no Brasil. A CAPES mantém o controle desse acesso, fazendo disso um mecanismo para exigir qualidade das pesquisas e programas de pós-graduação que desejam esse acesso. A descrição do portal, de seus critérios de acesso, sua importância para os programas de pós-graduação e para esta pesquisa será explicitada mais adiante na subseção sobre as IES que investem em pesquisa.
} 
oferta massificada e barata de ES à população brasileira em detrimento da sua qualidade (DURHAM, 2003; SCHWARTZMAN, 2004). As tentativas do Ministério da Educação em controlá-las através de supervisão e relatórios têm esbarrado no grande trabalho burocrático exigido para executá-lo. Mesmo sendo estas exigências extensas e minuciosas, ou por isso mesmo, sua ineficácia tem sido observada (CASTR0, 2012). Na tabela 2 se tem um panorama das IES por categoria acadêmica.

Tabela 2 - IES por categoria acadêmica

\begin{tabular}{lcccc}
\hline & Frequência & Porcentagem & $\begin{array}{c}\text { Porcentagem } \\
\text { Válida }\end{array}$ & $\begin{array}{c}\text { Porcentagem } \\
\text { Acumulada }\end{array}$ \\
\hline Centro Universitário & 125 & 5.3 & 5.3 & 5.3 \\
Faculdade & 2024 & 86.5 & 86.5 & 91.9 \\
Universidade & 190 & 8.1 & 8.1 & 100.0 \\
Total & 2339 & 100.0 & 100.0 & \\
\hline
\end{tabular}

Fonte: Instituto Nacional de Estudos e Pesquisas Educacionais (2010).

A categoria Faculdade, base da pirâmide em termos de autonomia institucional, representa a grande massa das IES, com $86,5 \%$ do total. Os centros universitários, um degrau acima das faculdades em termos de autonomia, têm uma representatividade menor que as universidades, o topo da pirâmide. Reunidos os centros universitários e as faculdades, vê-se que $91,9 \%$ das IES são instituições com autonomia restrita. 0 percentual reduzido de instituições autônomas ( $8,1 \%$ de universidades) levanta questões sobre os obstáculos que possam existir à mobilidade das IES nesta estrutura estratificada. Seria preciso analisar a dinâmica de entrada e saída das IES em cada uma das categorias. Sabe-se, entretanto, que muito dos órgãos e conselhos de supervisão e avaliação estatais e do Ministério da Educação são compostos por membros das próprias instituições que estão no topo da estrutura. Sabe-se também que as universidades públicas, 53,1\% do total de universidades (tabela 3), são criadas por atos legislativos e que, portanto, seu rebaixamento ao status de centros universitários e/ou faculdades enfrentaria um problema jurídico nada desprezível, o que indica também a força que estas instituições têm diante dos organismos cuja atribuição é supervisionar e avaliar o SES. 
Tabela 3 - Distribuição de universidades pública e privadas no Brasil

\begin{tabular}{lcccc}
\hline & Frequência & Porcentagem & $\begin{array}{c}\text { Porcentagem } \\
\text { Válida }\end{array}$ & $\begin{array}{c}\text { Porcentagem } \\
\text { Acumulada }\end{array}$ \\
\hline Privada com fins lucrativos & 19 & 10.0 & 10.0 & 10.0 \\
Privada sem fins lucrativos & 70 & 36.8 & 36.8 & 46.8 \\
Pública Estadual & 38 & 20.0 & 20.0 & 66.8 \\
Pública Federal & 58 & 30.5 & 30.5 & 97.4 \\
Pública Municipal & 5 & 2.6 & 2.6 & 100.0 \\
Total & 190 & 100.0 & 100.0 & \\
\hline
\end{tabular}

Fonte: Instituto Nacional de Estudos e Pesquisas Educacionais (2010).

A tabela 4 agrupa os dados relativos aos investimentos em pesquisa de IES por categoria acadêmica. Cada linha contém os dados relativos aos investimentos das IES daquela categoria. A coluna 'Soma' também se enquadra neste critério. A soma total de recursos investidos pelo SES como um todo foi de $\mathrm{R} \$ 703.644 .957,25$, não constando nesta tabela.

Tabela 4 - Investimento em pesquisa por categoria acadêmica

\begin{tabular}{lcccc}
\hline & Mínimo & Máximo & Soma & Total N \\
\hline Centro Universitário & .00 & 18808823.00 & 648559826.72 & 125 \\
Faculdade & .00 & 8269995.00 & 155143175.37 & 2024 \\
Universidade & .00 & 51483361.31 & 483641955.16 & 190 \\
\hline
\end{tabular}

Fonte: Instituto Nacional de Estudos e Pesquisas Educacionais (2010).

As universidades, apesar de um grupo restrito em relação às IES não autônomas, investem a grande maioria dos recursos em pesquisa e desenvolvimento no Brasil. 0 total de seus investimentos representa praticamente três vezes mais que o das faculdades. Com base nas limitações à autonomia institucional, analisadas na seção anterior deste artigo, é possível entender as razões para tanto. Ainda assim, são investidos 219,9 milhões de reais em pesquisa por faculdades e centros universitários, ou seja, IES que não dispõem das prerrogativas de autonomias para organizar pesquisa. As faculdades são responsáveis por 22,05\% dos investimentos em pesquisa, instituições estas que não têm qualquer exigência quanto à qualificação de seu corpo docente e não dispõem de nenhuma prerrogativa de autonomia. Os centros universitários são responsáveis por 9,22\% dos investimentos e, apesar de terem a exigência de manterem níveis mínimos de 
qualificação de seu quadro docente, sua missão institucional, estabelecida pelo Decreto 5.773 , é buscar a excelência no ensino e não na pesquisa científica, prerrogativa das universidades.

A tabela 5 agrupa os dados sobre investimentos em pesquisa das IES divididas em categorias administrativas.

Tabela 5 - Investimento em pesquisa por categoria administrativa

\begin{tabular}{lcccc}
\hline & Máximo & Mínimo & Soma & Total N \\
\hline Privada com fins lucrativos & 18808823.00 & .00 & 105186120.82 & 951 \\
Privada sem fins lucrativos & 40828118.80 & .00 & 228300852.17 & 1149 \\
Pública Estadual & 21038703.00 & .00 & 113498847.81 & 106 \\
Pública Federal & 51483361.31 & .00 & 247484296.47 & 62 \\
Pública Municipal & 4232653.21 & .00 & 9174839.98 & 71
\end{tabular}

Fonte: Instituto Nacional de Estudos e Pesquisas Educacionais (2010).

As IES privadas com e sem fins lucrativos representem $40 \%$ e $49 \%$ do total de IES respectivamente, mas a soma de seus investimentos em pesquisa tem uma representatividade menor no sistema. As privadas com fins lucrativos investem aproximadamente o equivalente às públicas estaduais. As privadas sem fins lucrativos investem aproximadamente 0 equivalente às públicas federais. Para uma melhor visualização da representatividade dos gastos de cada categoria no SES pode-se observar a tabela 6 .

Tabela 6 - Representatividade dos gastos por categoria administrativa.

\begin{tabular}{lcc}
\hline Categorias Administrativas & Soma & Porcentagem \\
\hline Privada com fins lucrativos & 105186120.82 & 14.95 \\
Privada sem fins lucrativos & 228300852.17 & 32.45 \\
Pública Estadual & 113498847.81 & 16.13 \\
Pública Federal & 247484296.47 & 35.17 \\
Pública Municipal & 9174839.98 & 1.30 \\
Total & 703644957.25 & 100.00 \\
\hline
\end{tabular}

Fonte: Instituto Nacional de Estudos e Pesquisas Educacionais (2010). 
Ao procurar pela frequência das IES que investem em relação às categorias administrativas, vê-se que a maioria em todas as categorias simplesmente não investe em pesquisa, com exceção das públicas federais (ver Tabela 7).

Tabela 7 - Frequência das IES que não investem por categoria administrativa.

\begin{tabular}{lcc}
\hline Categorias Administrativas & Frequência & Percentual do Total \\
\hline Privadas sem fins lucrativos & 706 & 61,44 \\
Privadas com fins lucrativos & 569 & 59,83 \\
Públicas estaduais & 75 & 67,92 \\
Públicas federais & 19 & 30,6 \\
Públicas municipais & 42 & 59,15 \\
\hline
\end{tabular}

Fonte: Instituto Nacional de Estudos e Pesquisas Educacionais (2010).

Enquanto que, no geral, $60,3 \%$ das IES não investem em pesquisa (1.411 instituições do total de 2.339), 30,6\% das IES públicas federais não fazem tais investimentos. As dificuldades das IES privadas para investir em pesquisa são compreensíveis, pois estas dependem dos recursos provenientes das taxas e mensalidades cobradas de seus estudantes, além dos recursos públicos recebidos não serem constantes ou fixos como no caso das IES públicas. Existem mecanismos de financiamento público de IES privadas, mas estes dependem do desenvolvimento e estruturação prévia, realizada com recursos próprios. Boa parcela dos recursos públicos destinados ao investimento em pesquisa depende da aprovação de conselhos acadêmicos ligados ao MEC ou ao Ministério de Ciência e Tecnologia (MCT). Os riscos envolvidos são, portanto, altos para IES privadas. Mas no caso das IES públicas, 67,92\% de IES estaduais que não investem em pesquisa pode ser considerado alto. A tabela 8 dá indícios que podem explicar esse fato. As faculdades públicas estaduais somam 68 unidades, mas apenas 1 delas investe quase a totalidade dos recursos em pesquisa. Na coluna em que consta 0 investimento máximo, é possível observar que apenas 1 faculdade pública estadual investe $\mathrm{R} \$ 7,4$ milhões, enquanto a soma total de investimentos é de $\mathrm{R} \$$ 7,7 milhões.

A mesma tabela proporciona uma visão geral do SES brasileiro. Nela agruparamse os dados relativos a investimento em pesquisa cruzando as categorias administrativas com as acadêmicas. Ela permitirá entrever que setor, público ou privado, investe mais em cada categoria acadêmica, ou seja, se investem mais sendo IES com plena autonomia institucional (universidades) ou de autonomia restritas (centros universitários e faculdades). 
Tabela 8 - Investimentos em pesquisa segundo Categorias acadêmicas e Categorias administrativas.

\begin{tabular}{lcccc}
\hline & Máximo & Mínimo & Soma & Total N \\
\hline Centro universitário & & & & \\
Privada com fins lucrativos & 18808823.00 & .00 & 32084648.40 & 27 \\
Privada sem fins lucrativos & 10421448.27 & .00 & 32478584.80 & 92 \\
Pública Municipal & $296,593.52$ & .00 & $296,593.52$ & 6 \\
\hline Faculdade & & & & 505 \\
Privada com fins lucrativos & 2173988.10 & .00 & 54933449.54 & 987 \\
Privada sem fins lucrativos & 8269995.00 & .00 & 88008661.79 & 68 \\
Pública Estadual & 7413111.82 & .00 & 7716639.28 & 4 \\
Pública Federal & 1875316.00 & .00 & 3726771.94 & 60 \\
Pública Municipal & $465,130.35$ & .00 & $757,652.82$ & 19 \\
\hline Universidade & & & & 70 \\
Privada com fins lucrativos & 5799003.13 & .00 & 18168022.88 & 38 \\
Privada sem fins lucrativos & 40828118.80 & .00 & 107813605.58 & 58 \\
Pública Estadual & 21038703.00 & .00 & 105782208.53 & 5 \\
Pública Federal & 51483361.31 & .00 & 243757524.53 & 8120593.64 \\
Pública Municipal & 4232653.21 & 274733.17 & \\
\hline
\end{tabular}

Fonte: Instituto Nacional de Estudos e Pesquisas Educacionais (2010).

Primeiramente se vê que não existem públicas estaduais ou federais entre os centros universitários. Os investimentos dessa categoria acadêmica são reduzidos, mas seu número total também o é. Já as faculdades privadas investem 0 equivalente às universidades privadas, sendo que o que muda é a média de investimentos dessas IES. Isto provavelmente se explica pelo fato de entre universidades privadas estarem as universidades confessionais, que surgiram na primeira metade do século XX e hoje são consideradas universidades de prestígio acadêmico no Brasil. Estas IES são tradicionalmente conhecidas no país e apresentam condições de investir uma boa quantidade de recursos em pesquisa. Schwartzman (2004) demonstrou em suas análises que, ao contrário do que se supunha, as IES privadas atraem uma porcentagem maior de estudantes provenientes das classes altas da população do que as IES públicas.

No entanto, quando se observam os gastos das universidades públicas, percebe-se que estas investem praticamente 3 vezes mais que as faculdades públicas. Além das faculdades não disporem de autonomia institucional, não são obrigadas a manter um 
quadro docente com qualificação mínima como as universidades e centros universitários. Este ambiente claramente restringe as possibilidades de se investir em pesquisa. Existem casos particulares de faculdades em áreas especializadas que contratam docentes com qualificação acadêmica e que, através destes, investem em pesquisa. Estes investimentos podem ser controlados através da aprovação de projetos de pesquisa por agências de fomento. Isto pode explicar parte dos investimentos em pesquisa por faculdades e sua capacidade de conduzi-las, apesar da falta de autonomia institucional e investimento no corpo docente.

0 que se observa aqui é um conflito entre a pressão que os quadros administrativos do Estado brasileiro exercem sobre o SES brasileiro, na tentativa de regulá-lo e diferenciá-lo, e a pressão dos grupos acadêmicos, que pressionam o SES em direção a um modelo de universidade de pesquisa. A valorização deste modelo pelos grupos acadêmicos através, por exemplo, dos financiamentos feitos por agências de fomento, sobrepõe-se às tentativas de diferenciação do SES por parte dos quadros administrativos. Mas, percebe-se também a influência indireta de grupos acadêmicos no Estado. A inexistência de centros universitários públicos demonstra tal influência, pois a especialização no ensino não é por eles valorizada. No setor público, portanto, criam-se universidades, ou, no caso de iniciativas mais localizadas (estaduais ou municipais) sem grandes recursos para investimento, criam-se faculdades. A valorização do modelo de universidade de pesquisa ficará clara com a análise dos critérios utilizados pela CAPES para dar acesso ao seu portal de banco de dados às IES.

A seguir se analisarão somente as IES que investem em pesquisa, observando quantas têm acesso ao portal CAPES, ferramenta fundamental para o desenvolvimento de pesquisas no SES brasileiro, uma vez que garante aos pesquisadores acesso a bases de dados nacionais e internacionais.

\section{A Condição das IES Que InVESTEM EM Pesquisa E DESENVOLVIMENTO}

A tabela 9 mostra quantas IES de cada categoria acadêmica têm acesso ao Portal CAPES. Este portal é uma das maiores ferramentas que os grupos acadêmicos dispõem hoje no Brasil para acessar revistas científicas, livros e bases de dados, em geral, do mundo inteiro. Existem outros portais disponíveis pela internet, mas o da CAPES é gratuito para as instituições que se enquadram em seus critérios: instituições federais de ES; instituições de pesquisa com pelo menos 1 programa de pós-graduação com nota 4 ou superior na avaliação da CAPES (numa escala que vai de 1 a 7); instituições públicas de ES, estaduais ou municipais, com pelo menos 1 programa de pós-graduação com nota 4 ou superior na avaliação da CAPES; instituições privadas de ES com pelo menos 1 doutorado que tenha nota 5 ou superior na avaliação da CAPES; 
Com os critérios citados percebe-se que as instituições federais recebem acesso automático ao portal da CAPES, inexistindo qualquer exigência para além de seu status administrativo. Por um lado, pode-se ver a ausência de um mecanismo de controle sobre instituições federais, lembrando que mais de $30 \%$ dessas instituições não investem em pesquisa. Mas, considerando as implicações de se ter ou não acesso ao portal, é de se questionar por que todas as IES não o têm. Observe-se que para desenvolver um programa de pós-graduação nota 4 ou superior é preciso realizar pesquisa. Portanto, estes critérios impelem para que instituições invistam em pesquisa sem ter sequer acesso a um portal de periódicos e de dados e independentemente se são IES que deveriam buscar a excelência no ensino.

Acessar bancos de dados e periódicos científicos é base dos profissionais do ES, independentemente se voltados à pesquisa, ao ensino ou mesmo à administração. A renovação do conhecimento científico é constante e a atualização dos professores é importante para a formação de seus estudantes. Obviamente, o acesso a publicações e a bases de dados é fundamental para o desenvolvimento de pesquisas, por ser este o meio que os acadêmicos consultam para atualizar seus conhecimentos e comunicar suas pesquisas com profissionais do mundo inteiro. Mesmo as funções administrativas de uma IES se beneficiam de dados levantados acerca da sua realidade externa regional/nacional, de outras IES e SES (nacionais e/ou internacionais), e dos trabalhos acadêmicos sobre as diferentes formas de gestão do ES que existem e são praticadas por IES do mundo todo.

Contudo, o que se observa é que a condição de instituições públicas, em especial as federais, garante um privilégio a seus profissionais, dando-lhes acesso privilegiado ao portal, em relação às IES privadas. Isso demonstra uma tentativa de sobrepor-se ao objetivo de diferenciação do SES através de categorias acadêmicas presentes nas normas do ES analisadas. A valorização da pesquisa está clara, pois um recurso básico como 0 acesso a um banco de dados é visto como premiação àquelas instituições que já conduzem pesquisas bem avaliadas por esse órgão de coordenação do sistema, com exceção das federais, que recebem 0 acesso de maneira automática. Além de impelir todas as IES que desejem o acesso ao portal a investir em pesquisa e programas de pósgraduação, independentemente se são universidades, faculdades ou centros universitários. 
Tabela 9 - Investimentos em pesquisa com e sem acesso ao portal Capes por categoria acadêmica.

\begin{tabular}{l|l|l|l}
\hline & Acesso ao portal Capes & Soma & Total N \\
\hline Centro Universitário & Não & 28277957,75 & 35 \\
& Sim & 36581868.97 & 35 \\
\hline Faculdade & Não & 83179942.11 & 379 \\
& Sim & 71963233.26 & 357 \\
\hline Universidade & Não & 22997123.37 & 17 \\
& Sim & 460644831.79 & 105 \\
\hline
\end{tabular}

Fonte: Instituto Nacional de Estudos e Pesquisas Educacionais (2010).

Basicamente 50\% das faculdades e centros universitários investem em pesquisa sem ter acesso a esse portal. Vê-se ainda que, no caso das faculdades, são investidos mais recursos em instituições sem acesso do que aquelas com acesso ao portal, lembrando que essa categoria representa $86,5 \%$ do universo de IES do censo. No caso desta última tabela, em que foram selecionadas apenas as IES que investem em pesquisa, as faculdades representam 79,3\% do total. A diferença de representatividade, como se pode observar, não é significativa. A realidade muda apenas com as universidades. A soma de investimentos das universidades com acesso ao portal é significativamente maior que as outras, totalizando 460 milhões de reais investidos. Ainda assim há 17 universidades sem acesso ao portal que investem ao todo quase 23 milhões em pesquisa.

Não há dúvidas que muito dinheiro é investido em IES sem uma condição básica para tanto, que é o acesso ao portal CAPES. A produção acadêmica tem como um de seus pilares a avaliação pelos pares dos resultados de pesquisas, sendo que a comunicação destes resultados é de extrema importância. Sem acesso ao portal essa comunicação será parcial, impedindo que pesquisadores avaliem com mais critérios a relevância de suas pesquisas, o que tem sido publicado, as críticas a determinadas teorias e metodologias científicas, correndo o risco inclusive de repetir desnecessariamente pesquisas de altos custos. Os critérios de acesso ao portal, como se viu, influenciam para que esta seja a realidade.

A tabela a seguir mostra o acesso ao portal CAPES com base nas categorias administrativas das instituições. 
Tabela 10 - Investimentos em pesquisa com e sem acesso ao Portal Capes por categoria administrativa

\begin{tabular}{l|l|l|l}
\hline & Acesso ao portal Capes & Soma & Total N \\
\hline Privada com fins lucrativos & Não & 44367214.99 & 205 \\
& Sim & 60818905.83 & 177 \\
\hline Privada sem fins lucrativos & Não & 81295080.14 & 202 \\
& Sim & 147005772.03 & 241 \\
\hline Pública Estadual & Não & 8062779.00 & 8 \\
& Sim & 105436068.81 & 23 \\
\hline Pública Federal & Não & $151,011.00$ & 2 \\
& Sim & 247333285.47 & 41 \\
\hline Pública Municipal & Não & $578,938.10$ & 14 \\
& Sim & 8595901.88 & 15 \\
\hline
\end{tabular}

Fonte: Instituto Nacional de Estudos e Pesquisas Educacionais (2010).

De acordo com a tabela 10 existem 2 IES públicas federais sem acesso ao portal da CAPES e que, mesmo assim, investem em pesquisa. Lembrando que um dos critérios para 0 acesso é ser uma instituição pública federal de ES, há a possibilidade dessas IES serem novas e estarem no processo de sua estruturação, daí a falta de acesso ao portal.

No caso das privadas, 49,33\% das que investem em pesquisa o fazem sem acesso ao portal. 0 montante de recursos gastos nestas condições representa 37,68\% do total. Considerando os critérios de acesso ao portal da CAPES, supõe-se que essas instituições não disponham de programas de pós-graduação bem desenvolvidos. A partir disso e considerando a menor representatividade de seus investimentos em relação à representatividade que elas próprias têm no universo de IES privadas, é possível inferir que disponham de menos incentivos para investir em pesquisa. Quando investem 0 fazem na ausência de parâmetros institucionais e legais, talvez apenas na tentativa de atingir os patamares mínimos definidos pela CAPES para acessarem o portal, mas também para terem acesso a recursos para eventos, pesquisas e bolsas. Programas de pós-graduação bem avaliados recebem bolsas das agências de fomento para seus estudantes, recursos para participação e realização de eventos e compra de equipamentos ${ }^{7}$. Investir em pesquisa sem tudo isso é mais arriscado e precário, ainda

\footnotetext{
${ }^{7}$ Infelizmente não existem variáveis nos microdados do censo que forneçam informações relativas ao acesso a recursos para eventos, bolsas, etc. 0 acesso ao portal CAPES é o único indicador de que se dispõe para avaliar o amparo à pesquisa fornecido por agências especializadas e pelo Estado brasileiro. Os
} 
mais em se tratando de IES privadas que dependem das taxas e mensalidades cobradas de seus estudantes para obterem recursos. É possível supor que as IES privadas que mais enfrentam essas dificuldades são, principalmente, as surgidas a partir da década de 1990 e que têm pouco prestígio acadêmico e poucas condições de competir com universidades públicas e privadas de prestígio, surgidas já na primeira metade do século XX. Mesmo assim, essas IES investem mais de 100 milhões de reais em pesquisa, um volume considerável que, como se viu, carece de parâmetros institucionais claros.

Além disso, instituições privadas devem ter doutorado com nota 5 ou superior nas avaliações da CAPES para conseguirem acesso ao portal. Entretanto, criar e manter um doutorado no setor privado e desenvolvê-lo para que obtenha esta nota (5 pontos de 7) apresenta dificuldades financeiras, sendo o custo de manutenção de um programa de pós-graduação muito maior que um curso de graduação. Atrair estudantes que optem pelo setor privado em detrimento do público, onde além de não pagarem para estudar podem concorrer a bolsas das agências de fomento e utilizá-las para si e não para pagarem mensalidades de estudo, é um empreendimento arriscado. Como já foi dito, as universidades privadas tradicionais entram automaticamente no grupo das IES beneficiadas pelos critérios CAPES, uma vez que foram estabelecidas antes da implantação dos critérios e normas aqui analisados.

Com os critérios mais brandos e mesmo automáticos no caso das IES públicas, uma quantidade muito maior de recursos é investidos em pesquisa em instituições que dêem condições a seus pesquisadores de comunicar livremente seus trabalhos com grupos acadêmicos do Brasil e do mundo. Ainda assim se constatou a situação vantajosa em que se encontram instituições federais em relação às demais, mais ainda em relação às privadas. 0 que se observa nessa relação é a sobreposição da coordenação do ES pelos quadros administrativos do Estado e pelos grupos acadêmicos. Os primeiros introduziram uma diferenciação no sistema, entre IES de pesquisa e de ensino, além de preverem, através das normas, um controle das IES recém surgidas do setor privado (as faculdades privadas). Já os grupos acadêmicos, que controlam as agências de fomento e coordenação como a CAPES, parecem interessados na consolidação de um modelo de universidade de pesquisa, favorecendo-o e induzindo as diferentes IES a se enquadrarem no mesmo, a despeito das categorias acadêmicas institucionalizadas.

\section{CONCLUSÃo}

Neste artigo, através da análise dos microdados do censo da educação superior de 2010, os investimentos em pesquisa foram cruzados com as diferentes categorias de IES e

critérios para esta forma de amparo, entretanto, são comuns às outras, vinculando a concessão de amparo à pesquisa à existência já de programas de pós-graduação bem avaliados pela CAPES. 
0 acesso que as mesmas têm ao portal da CAPES. Com base nessa análise é possível concluir com as análises realizadas que a capacidade do Estado regular o SES esbarra na influência estritamente acadêmica, que induz o SES brasileiro em direção a um modelo de universidade de pesquisa e que, além disso, favorece as instituições de prestígio consolidado antes da expansão do SES da década de 1990.

Ao analisar o teor das normas federais (Lei 9.394 de 1996 e o Decreto Presidencial 5.773 de 2006) e dos critérios utilizados pela CAPES para conceder acesso a sua base de dados, vê-se como a tentativa de coordenar o SES, por um e outro setor, acaba se sobrepondo, resultando em investimentos em pesquisa sem parâmetros institucionais claros. Os critérios que definem categorias acadêmicas introduzem uma diferenciação entre IES de pesquisa e IES orientadas ao ensino. Mas, os critérios definidos pela CAPES para dar acesso às IES ao seu portal de banco de dados e periódicos científicos, favorecem as IES públicas, especialmente as federais, além de induzirem todas as categorias acadêmicas de IES a investirem em pesquisa para então conseguirem o acesso (já que o principal critério é ter um programa de pós-graduação bem avaliado pela agência). Assim, um recurso básico do ES, como o acesso a um banco de dados, não é universalizado no sistema. 0 controle exercido é burocrático e interfere na dinâmica da relação entre IES, pois dá acesso automático a algumas categorias e controla rigidamente o de outras. Além da tensão entre tentativa de regulação estatal e regulação acadêmica, a sobreposição das mesmas termina por criar uma hierarquia entre IES de prestígio acadêmico, cujo topo é composto por algumas IES públicas (estaduais e federais) e as mais tradicionais IES privadas.

\section{REFERÊNCIAS}

BALBACHEVSKY, Elizabeth; HOLZHACKER, Denilde. Oliveira. A profissão acadêmica no Brasil: evolução nos últimos 10 anos. São Paulo: NUPPS, 2005. (Série Documentos de Trabalho, n. 2). Disponível em: <http://nupps.usp.br/downloads/docs/dt0502.pdf>. Acesso em: 11 jun. 2013.

BRASIL. Decreto $n^{0}$ 5.773, de 9 de Maio de 2006. Disponível em: $<$ http://www.planalto.gov.br/ccivil_03/_Ato2004-

2006/2006/Decreto/D5773.htm\#art79>. Acesso em: 30 out. 2012.

BRASIL. Lei $n^{o}$ 9.394, de 20 de dezembro de 1996. Disponível em: $<$ http://www.planalto.gov.br/ccivil_03/LEIS/19394.htm\#art54\%C2\%A72>. Acesso em: 30 out. 2012.

CALDERON, Adolfo Ignacio; LOURENCO, Henrique da Silva. Ensino superior privado: expansão das cooperativas de mão de obra docente. Cadernos de Pesquisa, São Paulo, v. 
41, n. 143, ago. 2011. Disponível em: $<$ http://www.scielo.br/scielo.php?script=sci_arttext\&pid=S0100-

15742011000200015\&lng=en\&nrm=iso > . Acesso em: 22 fev. 2013.

CASTR0, Maria Helena de Magalhães. Brazil bigher education policies and implementation. Campinas: Unicamp, 2012.

CUNHA, Luiz Antônio. Desenvolvimento desigual e combinado no ensino superior: estado e mercado. Educação e Sociedade, Campinas, v. 25, n. 88, out. 2004. Disponível em: $<$ http://www.scielo.br/scielo.php?script=sci_arttext\&pid=S010173302004000300008\&lng=en\&nrm=iso > . Acesso em: 22 fev. 2013.

DURHAM, Eunice R. O ensino superior no Brasil: público e privado. São Paulo: NUPES, 2003. n. 3.

GRAMANI, Maria Cristina N. A influência da qualidade na atratividade de instituições de ensino superior com capital aberto. Ensaio: Avaliação e Políticas Públicas em Educação, Rio de Janeiro, v. 16, n. 60, set. 2008. Disponível em: $<$ http://www.scielo.br/scielo.php?script=sci_arttext\&pid=\$0104$40362008000300007 \& \operatorname{lng}=$ en\&nrm=iso >. Acesso em: 22 fev. 2013.

INSTITUTO NACIONAL DE ESTUDOS E PESQUISAS EDUCACIONAIS - INEP. Número de cursos, matriculas, concluintes, vagas oferecidas, candidatos inscritos e ingressos 1991 a 2009. Brasília: Ministério da Educação, 2010. Disponível em: $<$ http://download.inep.gov.br/informacoes_estatisticas/2011/indicadores_educacionais/ historico/municipio_org_dep_1991_2009.zip>.Acesso em: 25 out. 2012.

SCHWARTZMAN, Simon. Equity, quality and relevance in higher education in Brazil. Anais da Academia Brasileira de Ciências, Rio de Janeiro, v. 76, n. 1, mar. 2004. Disponivel em: <http://www.scielo.br/scielo.php?script=sci_arttext\&pid=S000137652004000100015\&lng=en\&nrm=iso > . Acesso em: 25 fev. 2013. 